\title{
Giant intracranial epidermoids: is total removal feasible?
}

\author{
*Emad Aboud, MD, ${ }^{1}$ Mohammad Abolfotoh, MD, PhD, ${ }^{2,4}$ Svetlana Pravdenkova, MD, PhD, ${ }^{1}$ \\ Abdulkerim Gokoglu, MD, ${ }^{2}$ Murat Gokden, MD, ${ }^{3}$ and Ossama Al-Mefty, MD ${ }^{2}$
}

\begin{abstract}
${ }^{1}$ Arkansas Neuroscience Institute; ${ }^{3}$ Department of Pathology, University of Arkansas for Medical Sciences, Little Rock, Arkansas; 2Department of Neurosurgery, Brigham and Women's Hospital, Harvard University, School of Medicine, Boston, Massachusetts; and ${ }^{4}$ Department of Neurosurgery, Ain Shams University, Cairo, Egypt
\end{abstract}

OBJECT Epidermoid tumors arise from misplaced squamous epithelium and enlarge through the accumulation of desquamated cell debris. Optimal treatment consists of total removal of the capsule; therefore, giant and multicompartmental tumors are particularly challenging. A conservative attitude in handling the tumor capsule is common given concerns about capsule adherence to neurovascular structures, and thus the possibility of recurrence is accepted with the intent of minimizing complications. This study focuses on the outcome of surgery in patients with giant epidermoid tumors for which total capsule removal was the aim.

METHODS The authors conducted a retrospective analysis of all patients with giant epidermoid tumors treated by the senior author (O.A.), who pursued total removal of the capsule through skull base approaches. Patients were divided into 2 groups: one including patients with de novo tumors and the other consisting of patients who presented with recurrent tumors.

RESULTS Thirty-four patients had undergone 46 operations, and the senior author performed 38 of these operations in the study period. The average tumor dimensions were $55 \times 36 \mathrm{~mm}$, and 25 tumors had multicompartmental extensions. Total removal of the tumor and capsule was achieved with the aid of the microscope in $73 \%$ of the 26 de novo cases but in only $17 \%$ of the 12 recurrent tumor cases. The average follow-up among all patients was 111 months (range 10-480 months), and the average postsurgical follow-up was 56.8 months (range 6-137 months). There were 4 recurrences in the de novo group, and every case had had a small piece of tumor capsule left behind. One patient died after delayed rupture of a pseudoaneurysm. In the de novo group, the average preoperative Karnofsky Performance Scale (KPS) score was $71.42 \%$, which improved to $87.14 \%$ on long-term follow-up. In the group with recurrences, the KPS score also improved on long-term follow-up, from $64.54 \%$ to $84.54 \%$. In the de novo group, 3 cases (11.5\%) had permanent cranial nerve deficits, and 4 cases (15.4\%) had a CSF leak. In the recurrence group, 3 cases (25\%) had new, permanent cranial nerve deficits, and $1(8.3 \%)$ had a CSF leak. Two patients in this group developed hydrocephalus and required a shunt.

CONCLUSIONS Total removal of the capsule of giant epidermoid tumors was achieved in $73 \%$ of patients with de novo tumors and was associated with improved function, low morbidity and mortality, and a lower risk of recurrence. Surgery in patients with recurrent tumors was associated with higher morbidity and persistence of the disease.

http://thejns.org/doi/abs/10.3171/2014.11.JNS1481

KEY WORDS brain tumor; epidermoid cyst; epithelial capsule; skull base approaches; endoscopic techniques; microsurgical removal; oncology

\begin{abstract}
It is important, however, that the wall of the cyst, composed of a stratified squamous epithelium which is the only living, growing part of the neoplasm, be removed completely in order to prevent recurrence. Simple evacuation of the cyst will not suffice.
\end{abstract}

Paul Bucy ${ }^{8}$

Epidermoids, known as the "pearly tumor," are benign, slow-growing lesions that constitute $1.2 \%$ of brain tumors.
They are commonly believed to arise from misplaced stratified squamous epithelium during closure of the neural tube. They enlarge by accumulating desquamated epidermal cell debris and insinuate into the subarachnoid space, at times extending into multiple compartments. By the time a patient presents for medical attention, the

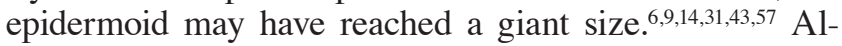
though many authors acknowledge that the ultimate goal

ABBREVIATIONS $\mathrm{CN}=$ cranial nerve; DWI = diffusion-weighted imaging; $\mathrm{KPS}=$ Karnofsky Performance Scale.

SUBMITTED January 14, 2014. ACCEPTED November 18, 2014.

INCLUDE WHEN CITING Published online January 16, 2015; DOI: 10.3171/2014.11.JNS1481.

DISCLOSURE The authors report no conflict of interest concerning the materials or methods used in this study or the findings specified in this paper.

* Drs. Aboud and Abolfotoh contributed equally to this work. 
of treatment is total removal of the capsule, a conservative attitude has prevailed because the capsule adheres to neurovascular structures at the cranial base (arteries, perforators, cranial nerves [CNs], and brainstem). Thus, many surgeons are inclined to leave part of the capsule behind, thereby accepting the risk of recurrence. $4,6,23,40,44,46,56$ Others advocate only a decompressive procedure with subtotal removal., ${ }^{710,38}$ Owing to the slow linear growth of the epithelium and the rate at which debris accumulates, ${ }^{5}$ recurrences are claimed to be late and are frequently underreported.

Regardless of the argument that the capsule is a mere remnant of epithelium, some epidermoids grow faster than natural epithelium and enlarge or recur through cellular proliferation, and thus act as a true benign neoplasm ${ }^{53}$ and even occasionally a malignant one $e^{1,11,27,36,37,47,53}$ with leptomeningeal metastasis from the intracranial malignant transformation of an epidermoid tumor. ${ }^{25,33}$ Furthermore, malignant conversion has been reported as the recurrence of a previously benign epidermoid..$^{21,53,54}$ Several investigators have commented that since the capsule is the "living portion" of the tumor,",,12,34 recurrence is inevitable with a residual capsule. Total removal of the capsule, which is now possible with microsurgical techniques, can prevent recurrence, and if only a minute portion of the capsule is overlooked during surgery, recurrence may at least be long delayed. This approach minimizes the complications associated with repeated surgery and subsequently improves patient outcome and quality of life. Furthermore, such an approach eliminates neoplastic or even malignant transformations.

The task of eliminating the epidermoid capsule is admittedly challenging, particularly in patients with giant tumors that extend into multiple compartments. This study is a retrospective analysis of a series of patients harboring giant epidermoid tumors that expanded into multiple compartments. They underwent surgery performed by the senior author (O.A.) with the goal of total removal of the capsule. This report aims to address the feasibility of total removal of the capsule of giant epidermoid tumors and its impact on complications and outcome. We postulated that total removal of the capsule not only prevents or delays recurrence but also minimizes complications and improves long-term outcome.

\section{Methods}

We conducted a retrospective study of all patients with intracranial epidermoid tumors surgically treated by the senior author (O.A.) in the period from 1987 through 2013. The aim of treatment was total removal of the tumor capsule. We reviewed each patient's clinical findings, images, operative procedures, postoperative outcome, and followup. As this is a retrospective study, it has the shortcomings of such a method, including selection bias, a span of more than 2 decades, and nonadjudicated outcome analysis. But the rarity of these tumors and the lengthy time period needed for study leads to such a method.

Patients were divided into 2 groups: those with de novo tumors without prior treatment and those having a tumor recurrence after surgery at another institution. In calculat- ing the total number of surgical procedures performed by the senior author in all patients, we counted second operations that were performed in patients in the de novo group, bringing the total to 38 . Tumor size was measured in two dimensions on MRI studies and was calculated using Centricity software (Centricity, GE Healthcare) and OsiriX for the Macintosh (OsiriX).

\section{Results}

The series comprised 34 patients, 18 males and 16 females, with an average age of 35.77 years (range 9-67 years) at the first surgery performed by any surgeon. Twenty-six patients had de novo tumors without prior treatment, and 8 patients had a recurrence after surgery at another institution. The average age at surgery for recurrence (12 cases) was 44.9 years (range $20-63$ years; Fig. 1). A total of 38 operations were performed for resection, 26 in patients with de novo tumors and 12 in those with recurrences (8 patients presented to us with recurrences, and 4 had recurrences after our initial surgery).

The average size of the tumor before surgery in the de novo group was $55.03 \times 35.48 \mathrm{~mm}$, while in the recurrence group it was $54.38 \times 38.73 \mathrm{~mm}$. The largest tumor measured $102 \times 76 \mathrm{~mm}$, while the smallest was $12 \times 26$ $\mathrm{mm}$. Before any surgery, $72 \%$ of the tumors had at least 1 diameter $\geq 40 \mathrm{~mm}$. These tumors had primary locations with extensions into various compartments in the same or adjacent cranial fossa. Details of the primary tumor locations and extensions for the 2 groups are summarized in Figs. 2 and 3.

\section{Clinical Findings}

The duration of symptoms in this series varied widely, from 5 days with hydrocephalus to a 30-year history of headache. The average duration of symptoms was 28.43 months. Symptoms also varied according to tumor location. Cranial nerve involvement was common in tumors in the cerebellopontine angle, while deteriorating vision was the most common presentation for patients with primary or secondary suprasellar epidermoids. Headache was common for tumors in any location and ranged from severe and

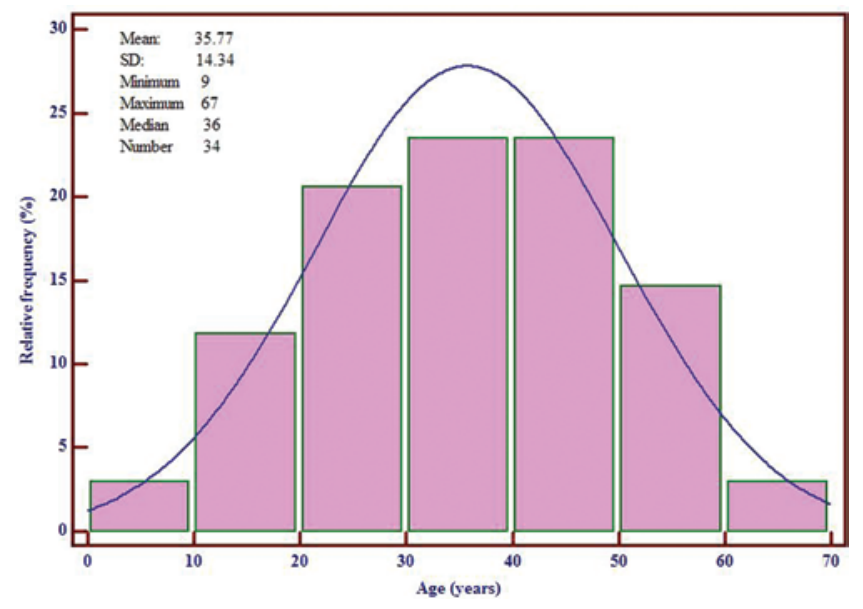

FIG. 1. The age distribution of patients at presentation. SD = standard deviation. 


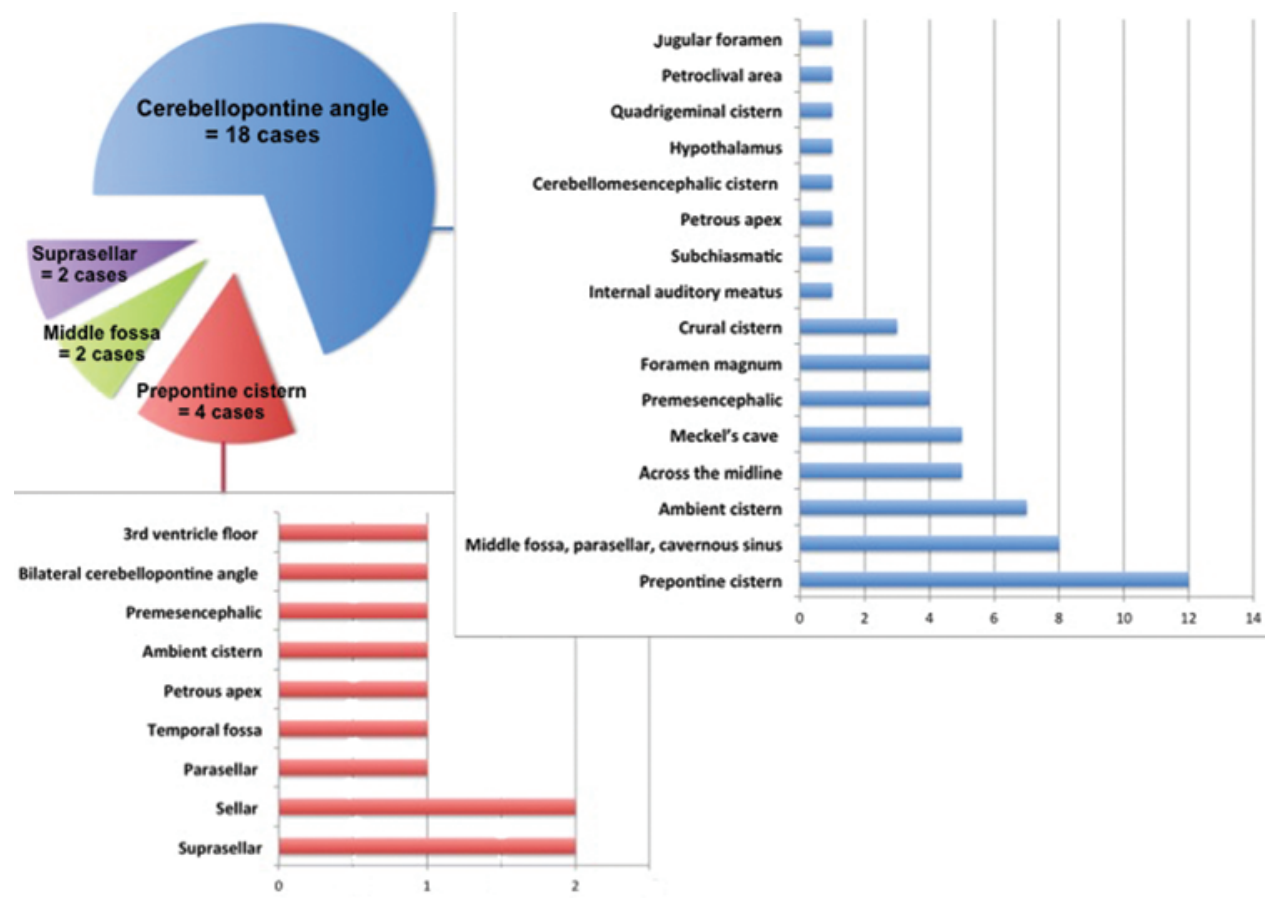

FIG. 2. De novo tumors involved 26 surgeries. Pie chart indicates distribution of primary tumor locations. Middle fossa refers to both the middle fossa and the temporal fossa. Bar graphs indicate the frequency of areas of extension of the cerebellopontine angle (right graph) and prepontine cistern (left graph) tumors. Temporal fossa refers to both the middle fossa and the temporal fossa. Figure is available in color online only.

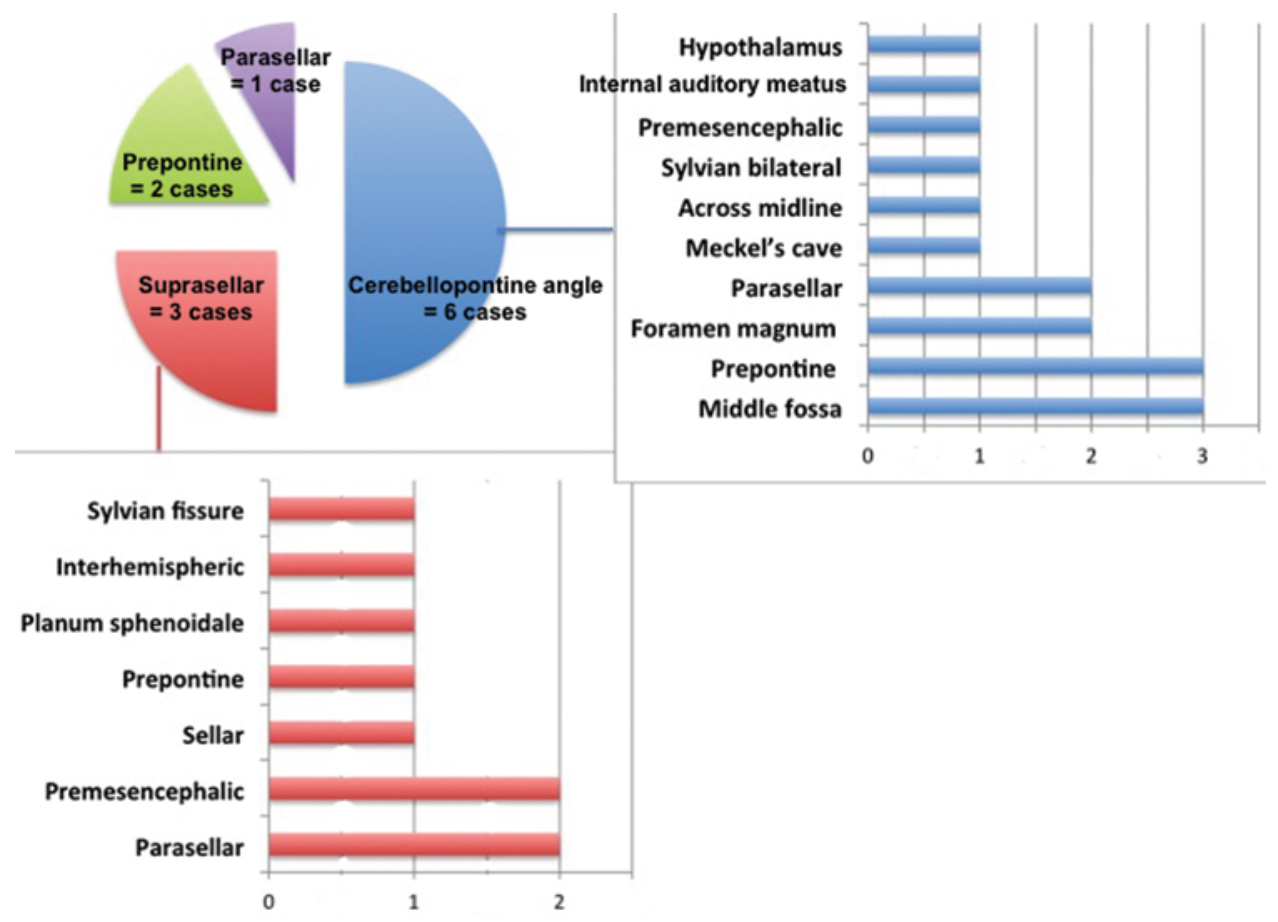

FIG. 3. Recurrent tumors involved 12 surgeries. Pie chart indicates distribution of primary tumor locations. Bar graphs indicate the frequency of areas of extension of the cerebellopontine angle (right graph) and the suprasellar (left graph) tumors. Figure is available in color online only. 
refractory to pain medication, to mild and lasting for years. The main symptoms at presentation are listed in Table 1.

\section{Imaging}

For all cases, we reviewed preoperative, postoperative, and follow-up MR images with and without gadolinium enhancement and diffusion-weighted images, as well as CT scans. Findings differed between the de novo and recurrent groups. Keratin contents were all positive in the diffusion sequences. Faint capsule enhancement was present in only 2 cases $(7.7 \%)$ in the de novo group, while the capsule enhanced significantly in 5 cases $(41.7 \%)$ in the recurrent group. Septation of the tumor was rare in patients with de novo tumors, occurring in only 4 cases (15.4\%), while it occurred in 5 cases $(41.7 \%)$ of recurrent tumor. At the second recurrence, all cases showed an enhanced capsule and multiloculation.

\section{Surgical Technique}

To achieve a wide exposure, to access all parts of the lesion, and to pursue total removal of the capsule, we used the skull base approaches listed in Table 2 and shown in Fig. 4. Because several CNs were compressed, involved, encased, or adherent to the brainstem (at times bilaterally), we used intraoperative neurophysiological monitoring, including somatosensory evoked potentials and brainstem auditory evoked responses, and extensive individual monitoring of all potentially involved CNs. Neuronavigation has been used routinely since 1993 .

After evacuating the keratin contents with controlled suction, the surgeon performs meticulous microdissection with two hands to tease adherent capsule from the arachnoid layer, thereby freeing the neurovascular structures. Traction is avoided and sharp microdissection is used (Fig. 5). In all de novo cases, a plane of dissection can be developed between the capsule and a compressed overlying arachnoid; it is essential to identify and confirm this plane and preserve it as long as possible. When it is unclear which portion is tumor capsule and which is arachnoid, a frozen section is sent for analysis (Fig. 6). If this analysis

TABLE 1. Signs and symptoms at presentation in 34 patients

\begin{tabular}{lc}
\hline \multicolumn{1}{c}{ Signs \& Symptoms } & \% of Patients \\
\hline Headache (variable degrees) & 42 \\
\hline Weakness (variable distributions) & 20 \\
\hline Hearing loss (variable degree) & 18 \\
\hline Diplopia & 16 \\
\hline Gait disturbance \& ataxia & 12 \\
\hline Trigeminal neuralgia & 12 \\
\hline Facial numbness & 10 \\
\hline Facial weakness (variable degree) & 10 \\
\hline Vertigo \& tinnitus & 8 \\
\hline Swallowing difficulty & 8 \\
\hline Seizures & 6 \\
\hline Deterioration of vision & 6 \\
\hline Hydrocephalus & 4 \\
\hline Hemifacial spasm & 2 \\
\hline
\end{tabular}

TABLE 2. Approaches used in 38 surgeries for epidermoid tumors

\begin{tabular}{lc}
\hline \multicolumn{1}{c}{ Surgical Approach } & No. of Cases \\
\hline Transmastoid retrosigmoid & 12 \\
\hline Combined petrosal & 8 \\
\hline Posterior petrosal & 6 \\
\hline Cranio-orbital zygomatic $^{\prime}$ & 5 \\
\hline Transcondylar $^{*}$ & 2 \\
\hline Pterional $^{*}$ & 2 \\
\hline Total petrosectomy $^{\prime}$ & 1 \\
\hline Zygomatic $^{\text {Anterior petrosal }}$ & 1 \\
\hline * Used twice in the same patient for 2 recurrences.
\end{tabular}

shows arachnoid only and no epithelial tissue, there is no need to pursue the membrane further.

In most of the patients with de novo tumors, the capsule was thin, avascular, or fibrotic and was easily dissected from neurovascular structures; however, it adhered to neurovascular structures in some cases (Fig. 7). Small perforators can traverse the contents of the cyst, perhaps because of the wrinkling or enfolding of the epithelial layer. In all surgeries for recurrent epidermoid tumors in this series, the capsule was thick and adhered to surrounding structures. We also noticed that the capsule became increasingly thick and fibrous with subsequent recurrences, a situation that can lead to the formation of loculated cysts of CSF or yellowish fluid that can compress surrounding structures.

The endoscope was used in 13 operations. It can reveal remnants of tumor hidden around the corner from the direct microscopic axis or into the foramina (internal auditory meatus, Meckel's cave, and jugular foramen). It assists in reaching a supratentorial extension when a purely posterior fossa approach is used (Fig. 5F).

The surgical site is walled off to minimize the spread of irritating substances and the risk of aseptic meningitis. Irrigation is used after resection is complete, and any debris is suctioned away. High doses of steroids are administered intraoperatively and slowly tapered over 2 weeks after surgery. Postoperative MRI is performed with diffusion sequences to verify gross removal of the contents and as a baseline for follow-up (Fig. 8).

\section{Extent of Resection}

Our evaluation of resection was based on the surgeon's notes in the operative reports regarding the extent of capsule removal. Microscopic total removal of the capsule was achieved in 19 cases (73\%) in the de novo group but in only $2(16.7 \%)$ of the 12 surgeries on recurrent tumors. Unfortunately, there is no postoperative imaging modality or tool that can be used to evaluate the degree of capsule resection. Diffusion weighted imaging confirms total removal of the contents, but postoperative DWI always showed bright signal in patients with a residual capsule from which all debris was thought to be totally removed (Table 3), probably because of microscopic flakes attached to the residual capsule. 

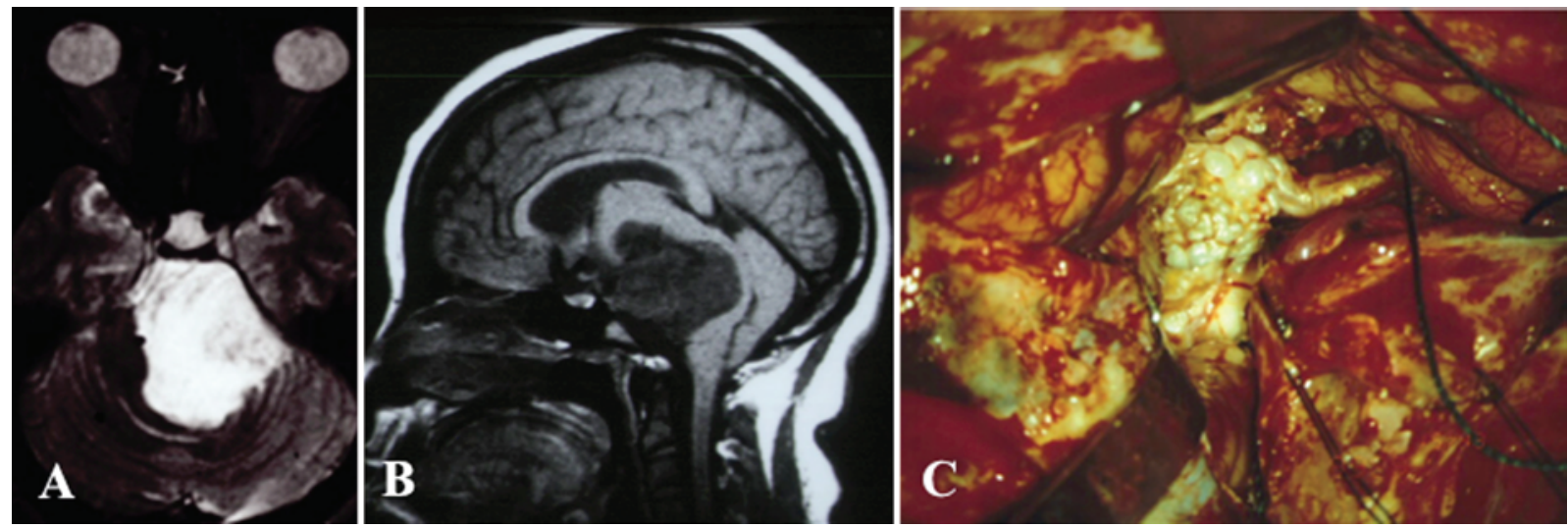

FIG. 4. A: Preoperative axial T2-weighted MR image showing the high-intensity epidermoid. B: Preoperative sagittal T1-weighted MR image showing the lesion. C: Intraoperative photograph depicting the wide exposure obtained through a posterior petrosal approach to a giant epidermoid tumor that extends infra- and supratentorially.

\section{Outcome}

The average follow-up was 111 months (range 10-480 months), and the average postsurgical follow-up was 56.8 months (range 6-137 months). There was one perioperative death (de novo group) from delayed rupture of a pseudoaneurysm after a suture repair of the A1 segment. In the de novo group, the average Karnofsky Performance Scale (KPS) score before surgery was $71.42 \%$ (range 50\%-90\%), which improved to $76.66 \%$ immediately after surgery and further improved to $87.14 \%$ during the follow-up period. In the group with recurrences, the average KPS score before surgery was $64.54 \%$ (range $60 \%-80 \%$ ). After surgery, this score improved immediately to $71.81 \%$ and continued to improve to $84.54 \%$ during the follow-up period. Table 4 shows the KPS scores, which were available in 31 patients.

Among the 26 de novo cases, new, permanent $\mathrm{CN}$ deficits occurred in 3 cases (11.5\%). Transient $\mathrm{CN}$ deficits occurred in 9 cases $(34.6 \%)$ and CSF leakage in 4 cases (15.4\%). Three patients with CSF leakage required reexploration and 1 patient had a seizure.

In the recurrence group, new, permanent $\mathrm{CN}$ deficits occurred in 3 cases (25\%), and transient $\mathrm{CN}$ deficits oc-
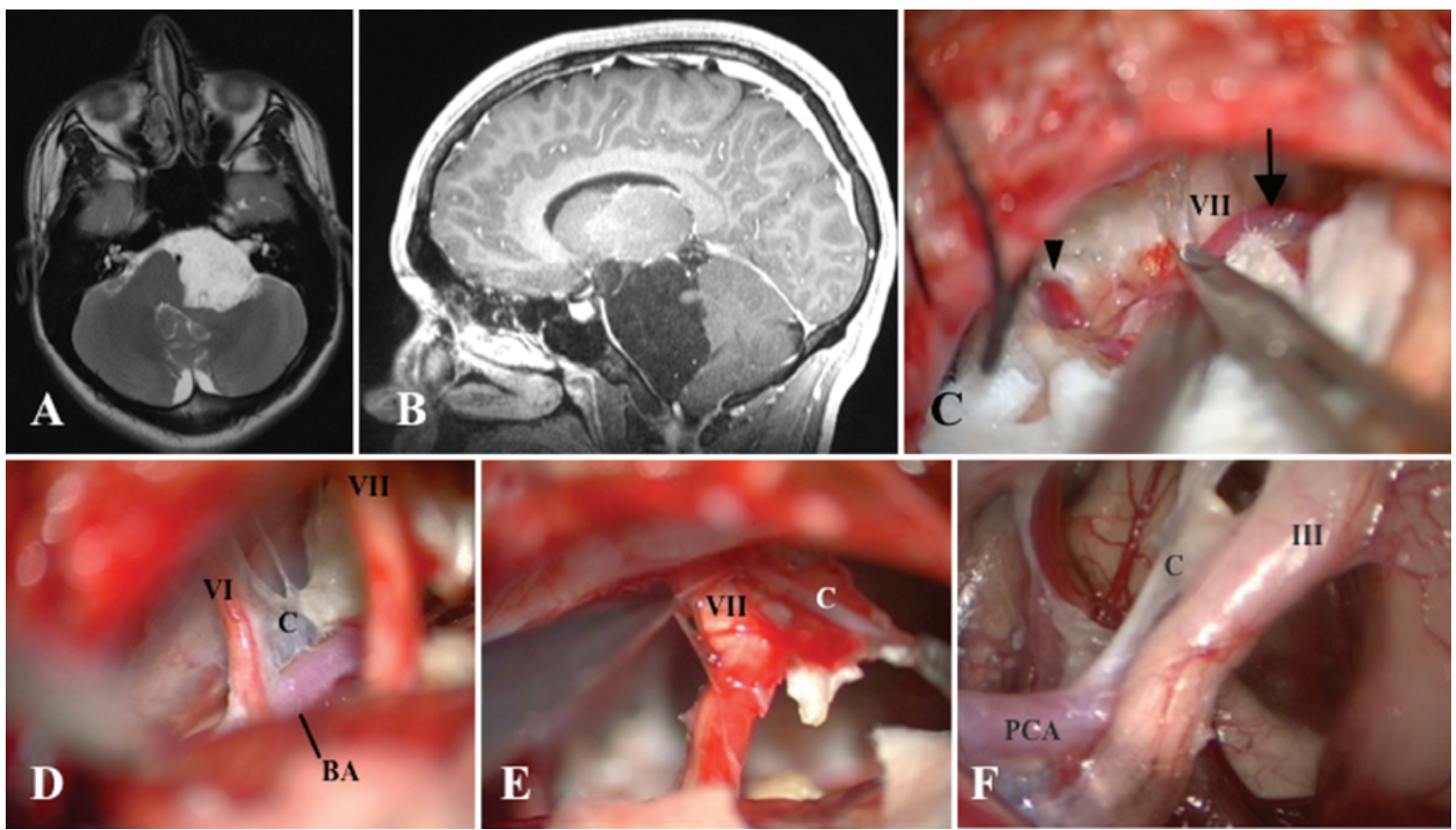

FIG. 5. A giant epidermoid tumor in the posterior fossa treated through a transmastoid retrosigmoid approach. A: Axial T2-weighted MR image. B: Sagittal T1-weighted MR image showing the suprasellar extension. C: Intraoperative photograph showing sharp dissection of the involved neurovascular structures. Arrow indicates the anterior-inferior cerebellar artery (AICA); arrowhead, the AICA-posterior inferior cerebellar artery trunk. D: Intraoperative photograph showing separation of the capsule from the thin arachnoidal layer engulfing the basilar artery (BA). E: Intraoperative photograph demonstrating the surgical field after a two-handed separation of the capsule from the arachnoid layer over CN VII. F: Intraoperative photograph showing hidden remnants that were pursued endoscopically for removal. $\mathrm{C}=$ tumor capsule; $\mathrm{PCA}=$ posterior cerebral artery; $I I I=$ oculomotor nerve; $\mathrm{VI}=$ abducens nerve; $\mathrm{VII}=$ facial nerve. 


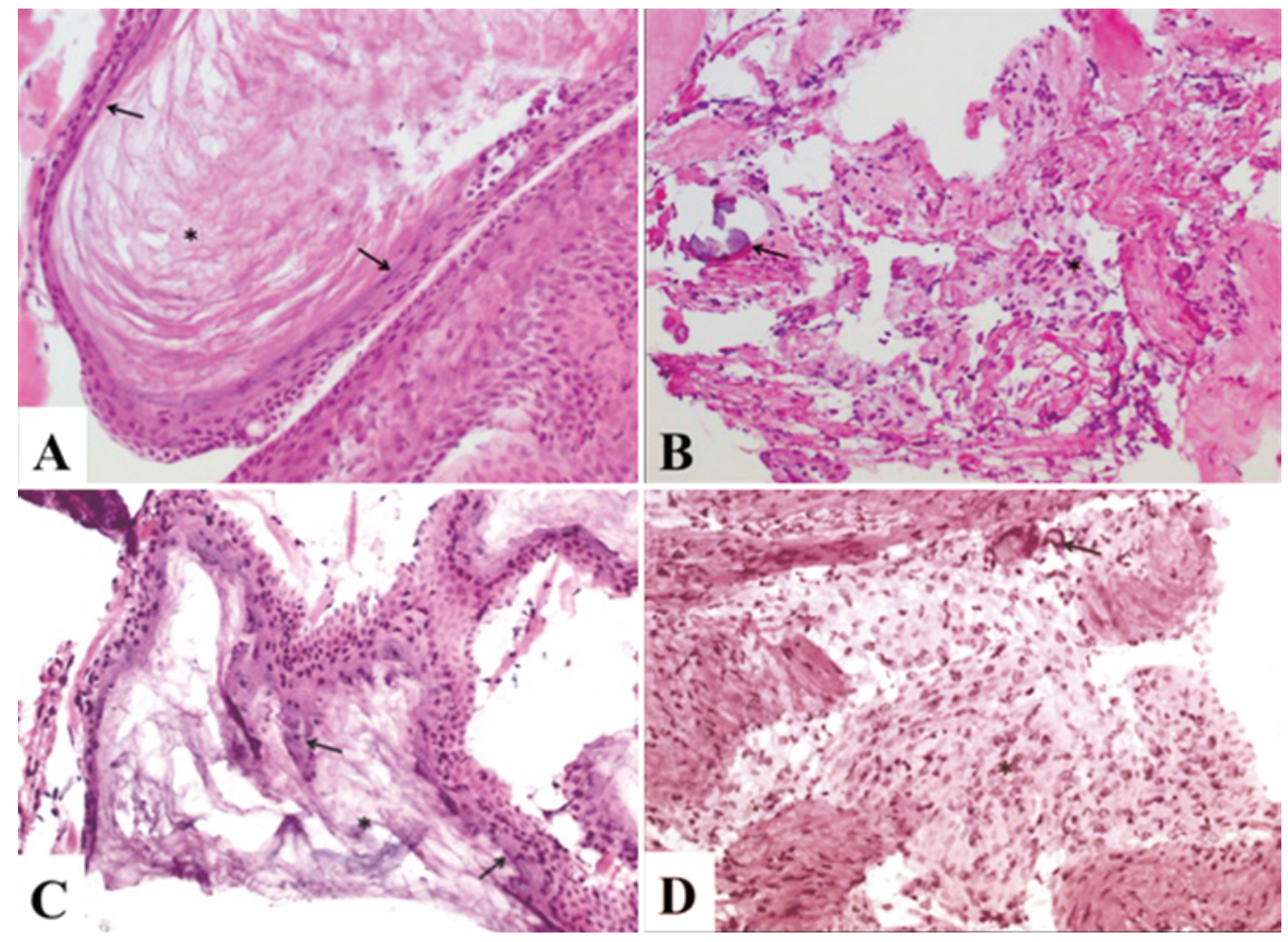

FIG. 6. A and B: Photomicrographs of frozen sections obtained from two patients during intraoperative consultation. The cyst wall has a stratified squamous epithelial lining along with a granular layer (arrows), and the cyst has epidermal keratinous contents (asterisks). C and D: Photomicrographs of frozen sections obtained from the same patients during intraoperative consultation. Note the arachnoid membrane with meningothelial cell groups (asterisks) along with psammomatous calcifications (arrows) commonly associated with these cells. No evidence of stratified squamous epithelium or keratin formation is visible. $\mathrm{H}$ \& $\mathrm{E}$, original magnification $\times 200$.

curred in 4 cases (33.3\%). CSF leakage requiring reexploration occurred in 1 case $(8.3 \%)$ and hydrocephalus requiring shunt placement occurred in 2 cases (16.7\%). In 3 cases of cerebellopontine angle tumors, in which a piece of tumor was left behind, multiple transient $\mathrm{CN}$ deficits and a recurrence developed. In the 8 patients who underwent initial surgery elsewhere, all had considerable postoperative residual tumor, as subtotal resection was the initial intent of surgery. Six of these patients $(75 \%)$ had permanent $\mathrm{CN}$ deficits from their original surgery.
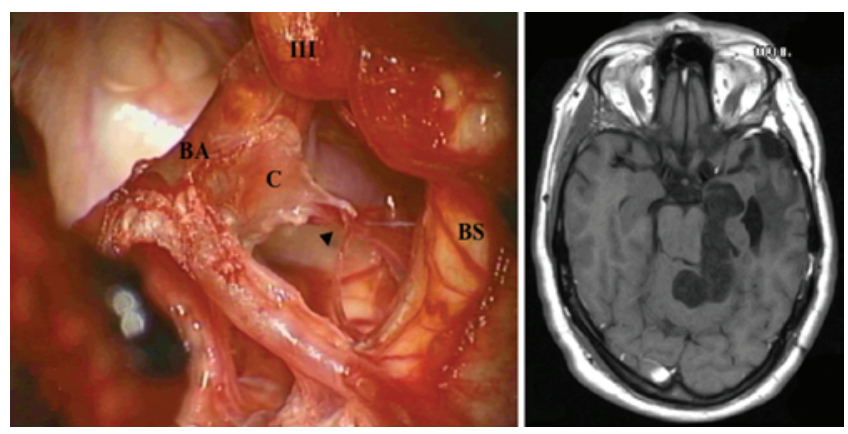

FIG. 7. A minute piece of tumor capsule was left behind, because of its adherence to the BA, and led to multiple recurrences. Left: Intraoperative photograph obtained at the original surgery. Arrowhead indicates the perforators. Right: Axial T1-weighted MR image showing a recurrence that extended to the quadrigeminal cistern. BS = brainstem.

\section{Recurrence}

Recurrence was diagnosed when progressive symptoms were associated with an increase in tumor size with a bright signal on DWI or extension into a new compartment. At recurrence, the tumor frequently changed its primary location, as it extended from the periphery of the original resection to other areas. Moreover, it showed more frequent capsule wall enhancement and multiloculations (Fig. 9). In the de novo group, 4 cases (15.4\%) had a recurrence, while 5 cases (41.7\%) in the recurrence group had a subsequent recurrence. In the de novo cases, we performed a Kaplan-Meier estimate to compare the rate of recurrence between 2 groups divided according to capsule removal: Group 1 had no residual capsule and Group 2 had a residual capsule (Fig. 10).

Follow-up was calculated for each operation. It was relatively short for patients with repeated recurrences, at an average of 56 months. The average calculated among all patients was 111 months. The average recurrence-free survival period after the first surgery was 121.5 months (range 33-150 months), while the recurrence-free period before the second recurrence decreased to 54.5 months (range 36-96 months).

\section{Discussion}

Epidermoids are benign lesions with rare reports of malignancy or malignant progression., ${ }^{7,44}$ There is no alter- 

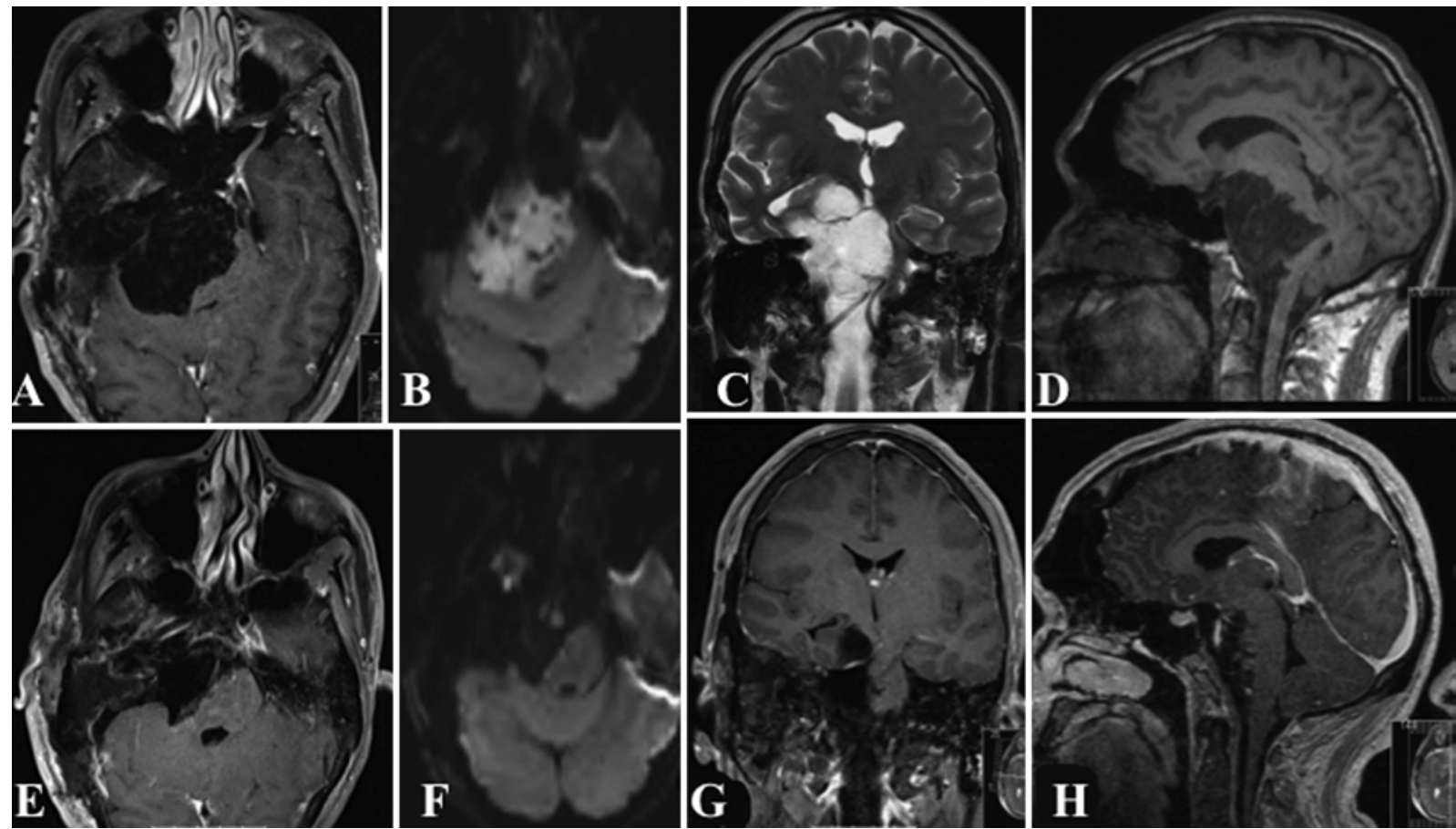

FIG. 8. An example of the emphasis on postoperative MRI studies for baseline follow-up, highlighting the importance of diffusion images. A: Preoperative axial enhanced T1-weighted MR image. B: Preoperative axial diffusion-weighted image with positive bright signal. C: Preoperative coronal T2-weighted MR image. D: Preoperative sagittal T1-weighted MR image. E: Postoperative axial T1-weighted MR image. F: Postoperative axial diffusion-weighted image showing no bright signal after total removal. G: Postoperative coronal T1-weighted MR image. H: Postoperative sagittal T1-weighted MR image.

native to surgery for epidermoid cysts, ${ }^{18,51,56,57}$ especially in younger patients. ${ }^{2,20,42}$ Since the squamous stratified epithelium that constitutes the capsule is the real disease, total removal of the capsule is acknowledged to be the ultimate treatment. ${ }^{8,18,51,57}$ Because the capsule adheres to the brainstem, CNs, and perforating arteries, however, a conservative attitude toward removal has prevailed, $, 6,22,40,44,46,51,56$ and many surgeons leave part of the capsule behind, accepting a higher risk of recurrence, especially for tumors extending into multiple sites. ${ }^{9,51}$ Deterred by the risk involved in dissecting the capsule, other authors have opted for a decompressive procedure by evacuating the contents ${ }^{7,38,44}$ or have not even attempted to handle the capsule. ${ }^{55}$

With a capsule remnant, recurrence is inevitable with time, and the capsule cannot be totally removed in recurrent cases. The use of microsurgical techniques, skull base approaches, intraoperative neurophysiological monitoring, neuronavigation, and endoscope-assisted dissection facilitates complete removal of these lesions in many cases. ${ }^{44,51,57}$ Our study shows that total capsule excision can be done in a large number of cases and not only minimizes future recurrence but is also associated with fewer complications

TABLE 3. Residual tumor after de novo and recurrent surgeries

\begin{tabular}{ccc}
\hline & \multicolumn{2}{c}{ No. of Cases (\%) } \\
\cline { 2 - 3 } Group & $\begin{array}{c}\text { Intraop Residual } \\
\text { Capsule }\end{array}$ & $\begin{array}{c}\text { Postop Residual } \\
\text { on DWI }\end{array}$ \\
\hline De novo (26 surgeries) & $7(26.9 \%)$ & $6(23.1 \%)$ \\
\hline Recurrent (12 surgeries) & $10(83.3 \%)$ & $11(91.7 \%)$ \\
\hline
\end{tabular}

after the first surgery. This approach also eliminates the added morbidity of repeated surgery that has such a drastic impact on patient quality of life, especially since patients are relatively young at their first presentation. ${ }^{2,4}$

\section{Surgical Outcome and Extent of Tumor Resection}

The early high rates of morbidity and mortality in patients with epidermoid tumors has fallen dramatically in the microsurgical era ${ }^{46,57}$ The most frequent surgical complications are aseptic meningitis and multiple $\mathrm{CN}$ deficits. Some authors commonly believe that surgical complications can be decreased by avoiding dissection of the capsule that adheres to neurovascular structures..$^{23,46,56}$ Lunardi and colleagues ${ }^{38}$ concluded that the absence of operative mortality among patients who underwent subtotal removal and the late recurrence justify subtotal removal.

We attempted total removal, diligently pursuing the capsule not only to diminish the chance of recurrence, but also to reduce complications. It is well known that the remnants of capsule and cyst material are the main causes of the aseptic meningitis and hydrocephalus described in some reports. ${ }^{7,24}$ Our findings are supported by an analysis of major, modern large series reported in the literature. Tables 5-7 list 22 major reports divided into 3 groups to compare the postoperative results of different strategies related to the degree of tumor resection: Group 1: conservative, total removal in less than $25 \%$ of cases; Group 2: moderate, total removal in $28 \%-60 \%$ of cases; and Group 3: extensive, total removal in more than $62 \%$ of cases. The mean rate of total removal was $12 \%$ in the first group, $46 \%$ in the second, and $78 \%$ in the third. 
TABLE 4. Karnofsky Performance Scale scores for 31 patients*

\begin{tabular}{|c|c|c|c|c|c|c|c|}
\hline \multirow[b]{2}{*}{ Group } & \multirow[b]{2}{*}{ Time } & \multicolumn{6}{|c|}{ No. of Cases } \\
\hline & & $100 \%$ & $90 \%$ & $80 \%$ & $70 \%$ & $60 \%$ & $50 \%$ \\
\hline \multirow[t]{3}{*}{ De novo (20 cases) } & Preop & & 2 & 8 & 3 & 6 & 1 \\
\hline & Immediate postop & & 6 & 9 & 3 & 1 & 1 \\
\hline & On FU & 7 & 10 & 2 & & & 1 \\
\hline \multirow[t]{3}{*}{ Recurrence (11 cases) } & Preop & & & 1 & 3 & 7 & \\
\hline & Immediate postop & & 1 & 4 & 5 & & 1 \\
\hline & On FU & 2 & 3 & 5 & & 1 & \\
\hline
\end{tabular}

FU = follow-up.

* Karnofsky Performance Scale score data were available in only 31 patients.

Mortality rates appear higher in Group 1 and certainly not less in Group 2, compared with Group 3, in which aggressive attempts were made to achieve a high percentage of total removal. Aseptic meningitis is more common in patients undergoing conservative approaches, probably because of the residual lesion's continuous direct contact with brain tissue and CSF after partial or subtotal removal. ${ }^{14,24,40,44,51}$ This complication was almost absent in our series and has been less frequent in other contemporary reports with high rates of total removal and, perhaps, the routine prolonged use of high doses of corticosteroids. ${ }^{17,45}$

A lower incidence of $\mathrm{CN}$ deficits was noted in a postoperative series with a high rate of total removal, ${ }^{32}$ but this result should be credited to the microsurgical techniques and intraoperative monitoring rather than to conservative handling of the capsule or the deliberate goal of subtotal removal. ${ }^{44,51,57}$ Furthermore, since our series comprised giant tumors that involved multiple $\mathrm{CNs}$, at times bilaterally, and a relatively low rate of postoperative $\mathrm{CN}$ deficits, we believe that the skull base approach is an important factor in minimizing postoperative $\mathrm{CN}$ deficits.

\section{Neuroimaging}

Epidermoid tumors usually appear as a low-density mass on CT and have low signal intensity on T1-weighted MRI, high signal intensity on T2-weighted images, and hyperintensity on diffusion sequences with no enhancement.
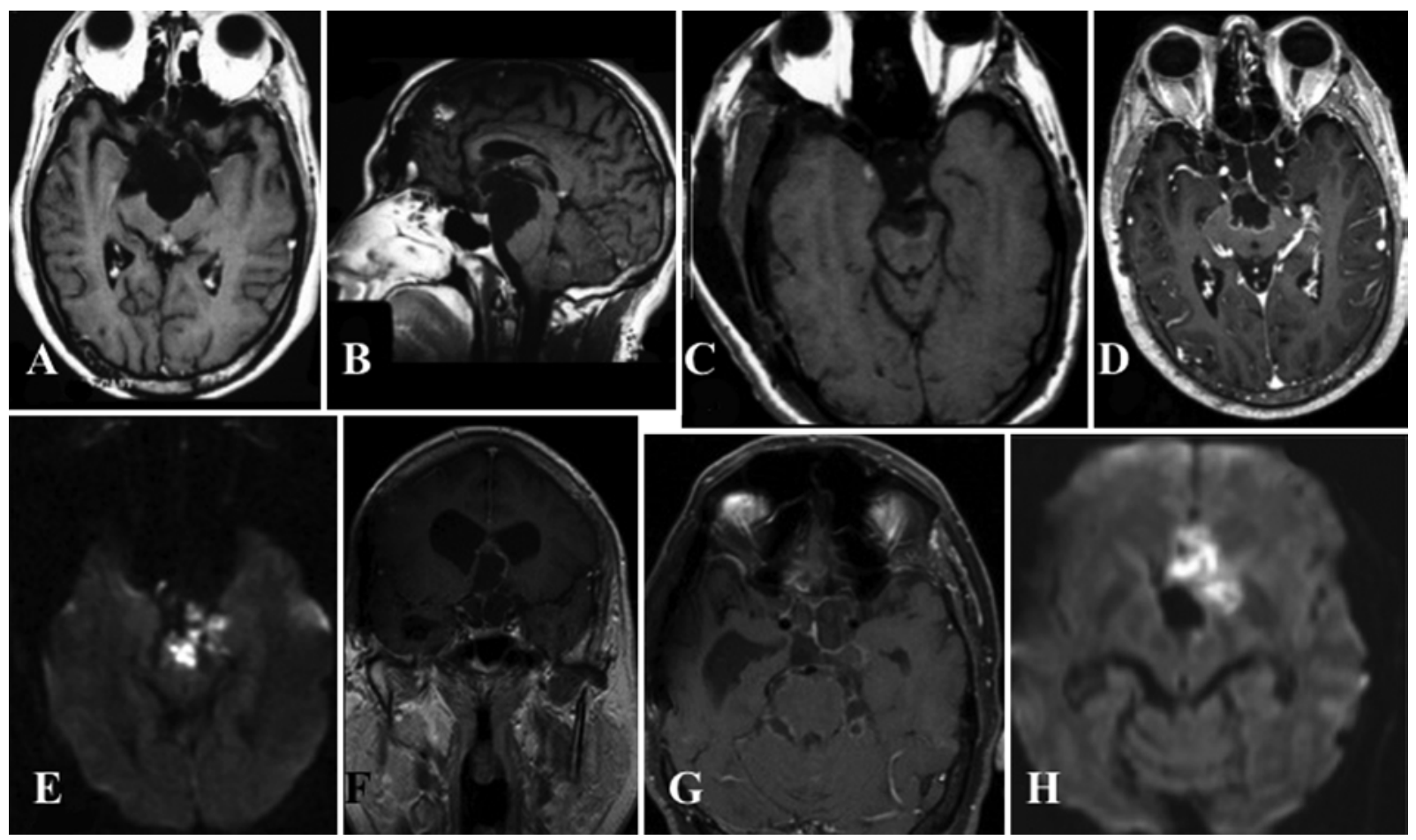

FIG. 9. An example of repeated recurrences with capsule enhancement, migration of the mass, and positive bright diffusion signals. Preoperative axial (A) and sagittal (B) T1-weighted MR images showing the tumor. Postoperative axial T1-weighted image (C) demonstrating residual tumor in the intrapeduncular cistern. Axial T1-weighted image (D) obtained at the time of the first recurrence, demonstrating capsular enhancement at the time of the first recurrence. Axial diffusion-weighted image $(E)$ showing positive signal when the patient was experiencing deteriorating vision. Coronal (F) and axial (G) enhanced T1-weighted images depicting tumor extension high in the suprasellar area and low around the brainstem at the second recurrence. Axial diffusionweighted image $(\mathrm{H})$ with positive bright signals at the second recurrence. 


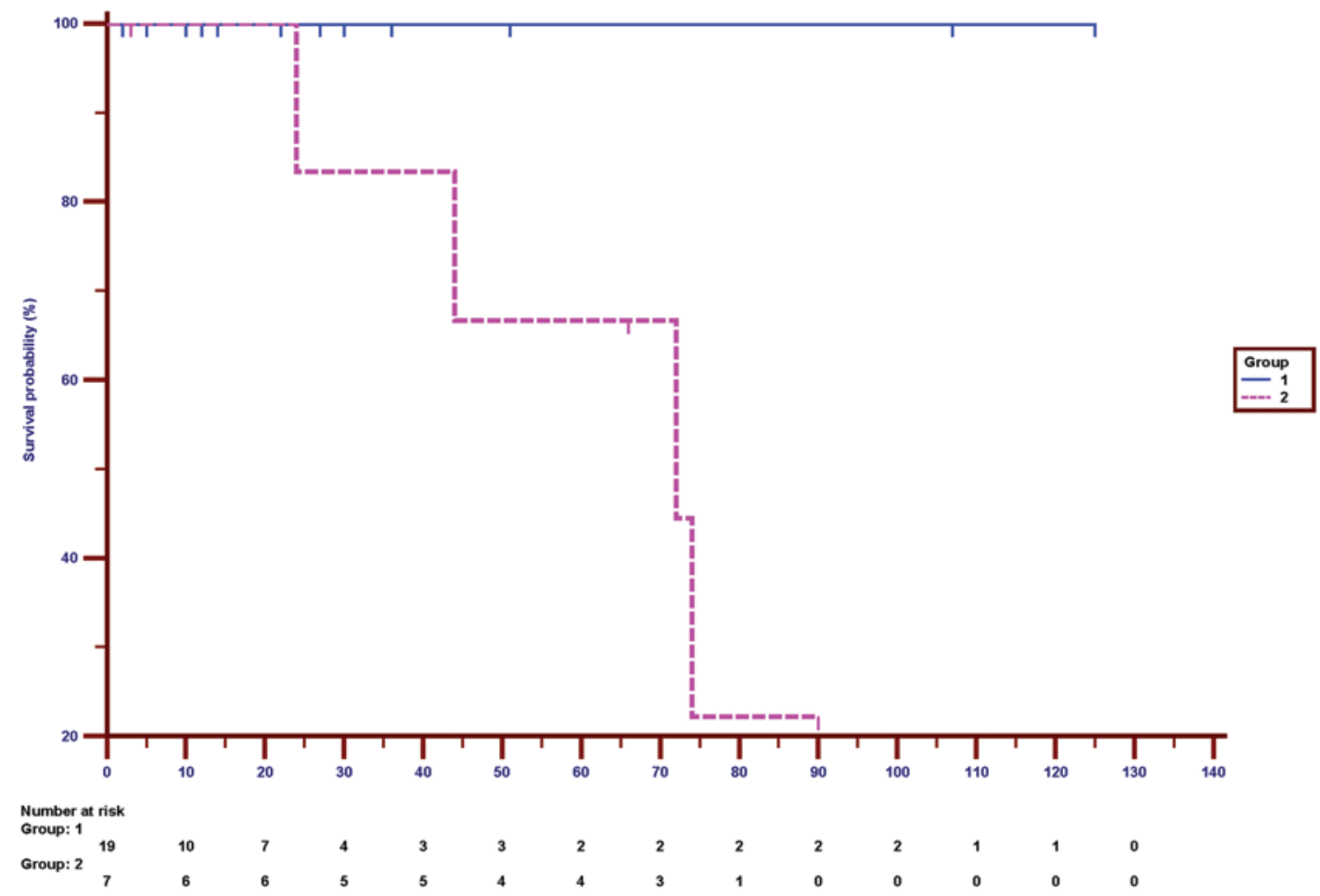

FIG. 10. Kaplan-Meier graph indicating the recurrence-free survival time for de novo cases divided into 2 groups, according to the extent of capsule removal (total removal or not): Group 1, no residual capsule; Group 2, residual capsule.

Calcification, hyperdensity, and marginal enhancement are rarely seen. ${ }^{3,14,26,28,29,41,50,51}$ Thus, these characteristics depict the contents of the cyst and aid in the accurate preoperative diagnosis. Postoperative imaging can only confirm removal of the cyst contents by the absence of hyperintensity on diffusion studies. Follow-up radiographic monitoring is crucial for detecting tumor recurrence through an increase in the size of residual lesions. Magnetic resonance imaging is the best modality for documenting tumor growth.

Occasionally, partial or moderate rim enhancement has been reported, particularly with a recurrence, and is frequently caused by reactive granulation. ${ }^{21}$ Nonetheless, this enhancement has been thought to be an indication of neoplastic proliferation or a manifestation of malignancy. ${ }^{1}$ Our cases with obvious enhancement did not show signs of malignancy. Radiological confirmation of recurrence is not always easy. The cavity that remains after tumor has been excised fills with CSF, which appears on CT scans as a low-density area that resembles the original tumor and may be confused with recurrence. ${ }^{18,39,51}$ Multiple loculations on MRI and enhancement of the periphery further cloud the picture. Therefore, intervention for a recurrence should be based on documented clinical symptoms or a progressive, compressive accumulation seen on DWI, which can solely differentiate an epidermoid from a retained cyst or encephalomalacia, especially in patients with multiple recurrences. ${ }^{46,50,51}$

\section{Recurrence and Late Outcome}

With a residual capsule, recurrence is inevitable given that the epidermoid cyst is a mere accumulation of cellular debris from a remnant of keratinized squamous epi- thelium. The variable rate of recurrence reported in the literature is attributed to a short follow-up period. ${ }^{32,45,55} \mathrm{As}$ Tables 5-7 show, recurrence rates were lower in Group 3 (a higher rate of total removal) for comparable follow-up periods in the other groups.

Given a hypothesis of linear growth and a constant rate of debris accumulation, it is believed that the time required for the recurrence of a tumor the same size as the original is equal to the patient's age at the initial surgery plus 9 months. ${ }^{5}$ Justifying the practice of subtotal removal and conservative handling of the capsule, ${ }^{7,44,46,57}$ this hypothesis assumes that as little as a single cell remains postoperatively and that the recurring mass grows at the same rate as the original tumor. ${ }^{44}$

Multiple investigators suggest that the actual proliferation of this epithelium beyond the normal remnant should be considered a neoplasm, ${ }^{51,53}$ even with an incidence of malignant progression; hence, they should be treated the same as other benign tumors for which surgical removal is the goal. Echoing other authors, ${ }^{19,24}$ Altschuler and associates $^{4}$ stated that repeated surgical attempts on these tumors are difficult and fraught with neurological complications for the patient. Repeated surgery is associated with accumulated deficits and morbidity and the expectation of another surgery. ${ }^{51}$ With repeated surgery, an inflammatory reaction with severe adhesion takes place, and the opportunity for total removal is lost. Moreover, the period between surgical interventions shortens with every recurrence. These findings emphasize that results are better and recurrence is delayed when resection of the tumor and capsule is as close to complete as possible.

One of the most important factors that facilitate total 


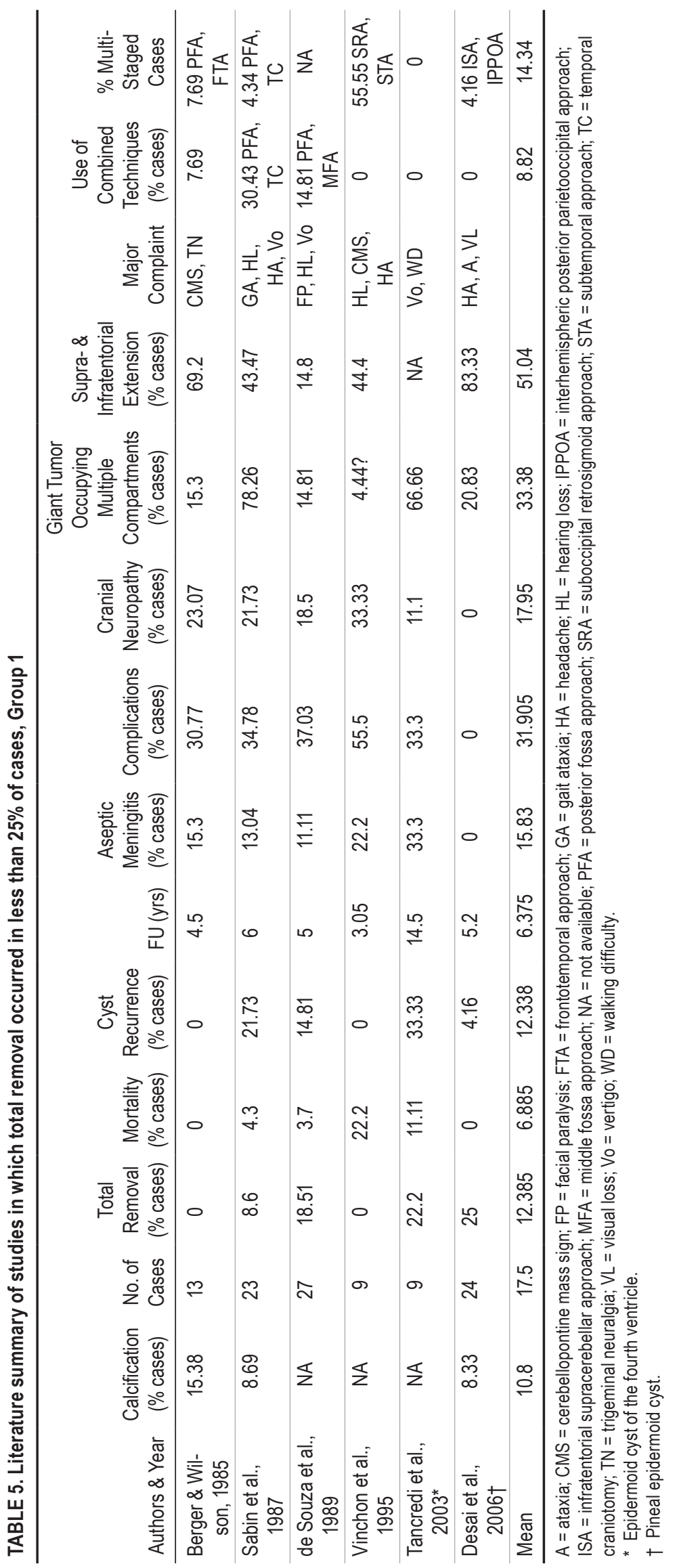




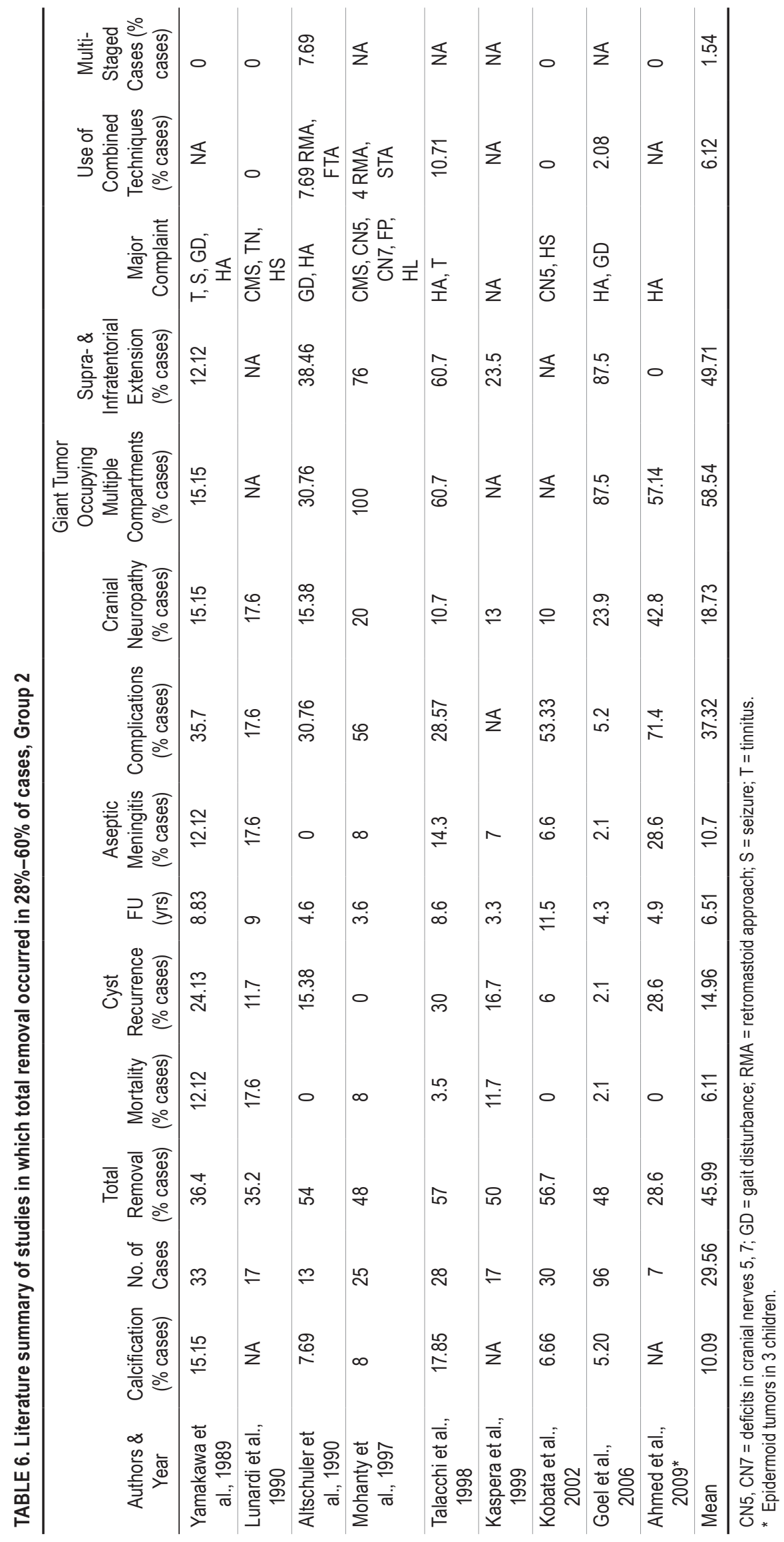




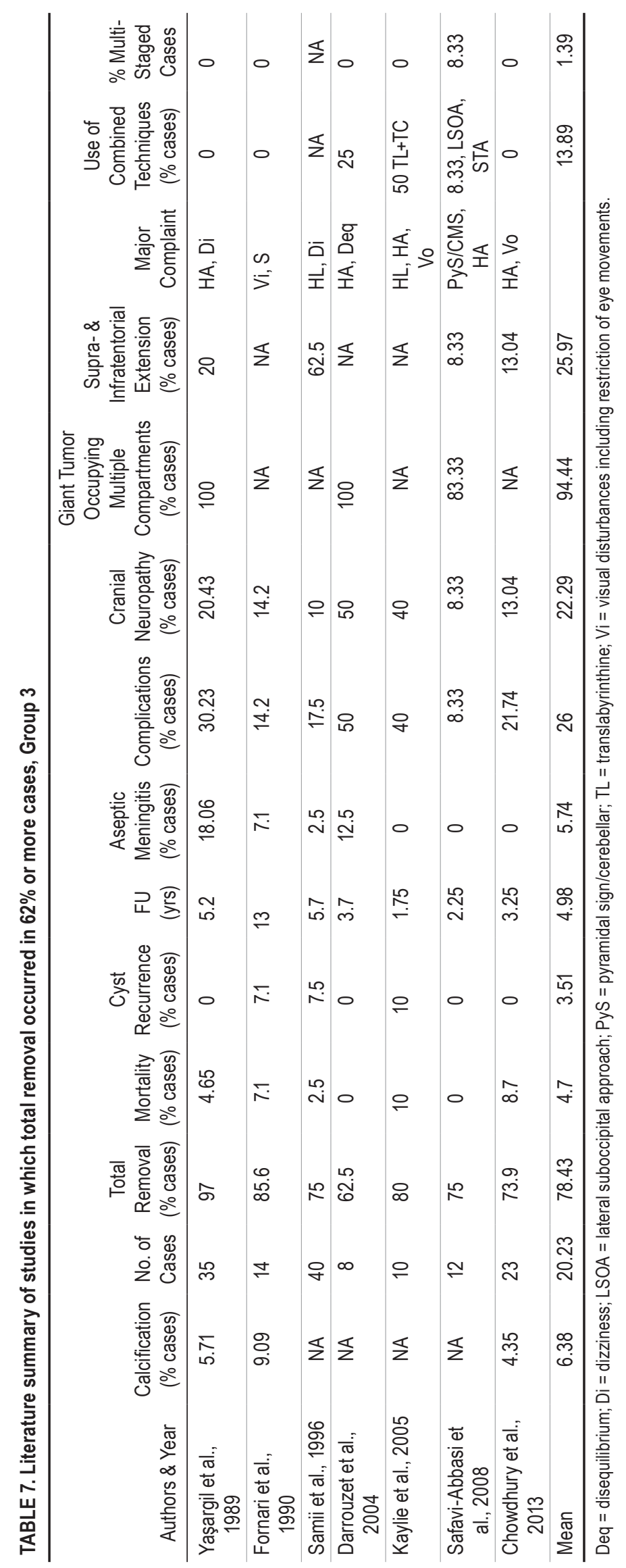


removal is adequate exposure of the lesion. ${ }^{32,49,51}$ In the patients who came to us with a recurrence, exposure during the previous surgery had been limited and did not allow access to all extensions of the tumor, preventing the surgeon from resecting the capsule in these regions. We extended the previous approaches with wide skull base exposures $^{3}$ to allow better access to all portions of the tumor.

\section{Giant Tumors and Extent of Resection}

Both old and recent series in the literature include some cases of giant tumors that extend into multiple compartments. ${ }^{4,40,44}$ These tumors are formidable, and the goal of total removal of the capsule is quite challenging. These cases have been fraught with a high risk of failure and recurrence. ${ }^{40,44}$ In such cases, surgeons have resorted to subtotal resection or a staged operation through 2 different approaches: the use of an endoscope to visualize beyond the restrictive limits of the traditional approach or the use of a combined infra- and supratentorial approach. ${ }^{15,44,48}$ Altschuler and colleagues ${ }^{4}$ found that patients who required multiple procedures resulting in fixed deficits had an extensive lesion and incomplete initial resection, which they believed to be attributable to a limited initial exposure. They contemplated whether the use of a more extensive approach in a first operation would have resulted in better tumor resection, improved outcome, and reduced recurrence.

We strongly believe, and the results of our study confirm, that full exposure through a skull base approach not only increases the likelihood of total removal of this lesion, including the capsule, but also alleviates operative complications, CN deficits, and aseptic meningitis. Our findings support the role of a skull base approach in effectively and safely removing the capsule.

\section{Conclusions}

Total removal and complete resection of the capsule can be achieved in the majority of patients with giant epidermoids and is associated with low morbidity and mortality. This goal is facilitated by a thorough preoperative evaluation, an approach that allows wide exposure, sharp microsurgical removal, extensive intraoperative $\mathrm{CN}$ monitoring, an endoscope-assisted technique, and neuronavigation. The pursuit of total capsule removal minimizes not only recurrences but also the risk of postoperative aseptic meningitis, $\mathrm{CN}$ deficits, and subsequent complications from repeated surgery for recurrences.

\section{Acknowledgments}

We are grateful to Dr. Linda Bi and Julie Yamamoto for editorial assistance.

\section{References}

1. Abramson RC, Morawetz RB, Schlitt M: Multiple complications from an intracranial epidermoid cyst: case report and literature review. Neurosurgery 24:574-578, 1989

2. Ahmed I, Auguste KI, Vachhrajani S, Dirks PB, Drake JM, Rutka JT: Neurosurgical management of intracranial epidermoid tumors in children. Clinical article. J Neurosurg Pediatr 4:91-96, 2009
3. Al-Mefty O: Lesions of the posterior cranial base, in: Surgery of the Cranial Base. Boston: Kluwer Academic Publishers, 1989, pp 209-238

4. Altschuler EM, Jungreis CA, Sekhar LN, Jannetta PJ, Sheptak PE: Operative treatment of intracranial epidermoid cysts and cholesterol granulomas: report of 21 cases. Neurosurgery 26:606-614, 1990

5. Alvord EC Jr: Growth rates of epidermoid tumors. Ann Neurol 2:367-370, 1977

6. Baumann $\mathrm{CH}$, Bucy PC: Paratrigeminal epidermoid tumors. J Neurosurg 13:455-468, 1956

7. Berger MS, Wilson CB: Epidermoid cysts of the posterior fossa. J Neurosurg 62:214-219, 1985

8. Bucy PC: Intradiploic epidermoid (cholesteatoma) of the skull. Arch Surg 31:190-199, 1935

9. Burger PC, Vogel FS: Epidermoid and dermoid cysts, in: Surgical Pathology of the Nervous System and Its Coverings, ed 2. New York: John Wiley \& Sons, 1982, pp 117-122

10. Caemaert J: Endoscopic neurosurgery, in Schmidek HH (ed): Schmidek \& Sweet Operative Neurosurgical Techniques: Indications, Methods, and Results, ed 4. Philadelphia: WB Saunders, 2000, Vol 1, pp 535-570

11. Cannon TC, Bane BL, Kistler D, Schoenhals GW, Hahn M, Leech RW, et al: Primary intracerebellar osteosarcoma arising within an epidermoid cyst. Arch Pathol Lab Med 122:737-739, 1998

12. Carmel PW: Brain tumors of disordered embryogenesis, in Youmans JR (ed): Neurological Surgery, ed 4. Philadelphia: WB Saunders, 1996, Vol 4, pp 2761-2781

13. Chowdhury FH, Haque MR, Sarker MH: Intracranial epidermoid tumor; microneurosurgical management: an experience of 23 cases. Asian J Neurosurg 8:21-28, 2013

14. Conley FK: Epidermoid and dermoid tumors: clinical features and surgical management, in Wilkins RH, Rengachary SS (eds): Neurosurgery. New York: McGraw-Hill, 1985, pp 668-673

15. Darrouzet V, Franco-Vidal V, Hilton M, Nguyen DQ, LacherFougere S, Guerin J, et al: Surgery of cerebellopontine angle epidermoid cysts: role of the widened retrolabyrinthine approach combined with endoscopy. Otolaryngol Head Neck Surg 131:120-125, 2004

16. de Souza CE, Sperling NM, da Costa SS, Yoon TH, Abdel Hamid M, de Souza RA: Congenital cholesteatomas of the cerebellopontine angle. Am J Otol 10:358-363, 1989

17. Desai KI, Nadkarni TD, Fattepurkar SC, Goel AH: Pineal epidermoid cysts: a study of 24 cases. Surg Neurol 65:124129,2006

18. Fein JM, Lipow K, Taati F, Lansem T: Epidermoid tumor of the cerebellopontine angle: diagnostic value of computed tomographic metrizamide cisternography. Neurosurgery 9:179-182, 1981

19. Fiume D, Gazzeri G, Spallone A, Santucci N: Epidermoid cysts of the fourth ventricle. Surg Neurol 29:178-182, 1988

20. Fornari M, Solero CL, Lasio G, Lodrini S, Balestrini MR, Cimino C, et al: Surgical treatment of intracranial dermoid and epidermoid cysts in children. Childs Nerv Syst 6:66-70, 1990

21. Fox H, South EA: Squamous cell carcinoma developing in an intracranial epidermoid cyst (cholesteatoma). J Neurol Neurosurg Psychiatry 28:276-281, 1965

22. Gelabert-González M: [Intracranial epidermoid and dermoid cysts.] Rev Neurol 27:777-782, 1998 (Span)

23. Goel A, Muzumdar D, Desai K: Anterior tentorium-based epidermoid tumours: results of radical surgical treatment in 96 cases. Br J Neurosurg 20:139-145, 2006

24. Guidetti B, Gagliardi FM: Epidermoid and dermoid cysts. Clinical evaluation and late surgical results. J Neurosurg 47:12-18, 1977

25. Hamlat A, Hua ZF, Saikali S, Egreteau J, Guegan Y: Malig- 
nant transformation of intracranial epidermoid cyst with leptomeningeal carcinomatosis: case report. Acta Neurol Belg 103:221-224, 2003

26. Handa J, Okamoto K, Nakasu Y, Nakasu S, Nakano Y: Computed tomography of intracranial epidermoid tumours with special reference to atypical features. Acta Neurochir (Wien) 58:221-228, 1981

27. Hoeffel C, Heldt N, Chelle C, Claudon M, Hoeffel JC: Malignant change in an intradiploic epidermoid cyst. Acta Neurol Belg 97:45-49, 1997

28. Kallmes DF, Provenzale JM, Cloft HJ, McClendon RE: Typical and atypical MR imaging features of intracranial epidermoid tumors. AJR Am J Roentgenol 169:883-887, 1997

29. Karantanas AH: MR imaging of intracranial epidermoid tumors: specific diagnosis with Turbo-FLAIR pulse sequence. Comput Med Imaging Graph 25:249-255, 2001

30. Kaspera W, Majchrzak H, Banc K, Lelek P: [Clinical course and results of surgical treatment of epidermoid and dermoid tumors.] Neurol Neurochir Pol 33:97-117, 1999 (Polish)

31. Kavar B, Kaye AH: Dermoid, epidermoid and neuroenteric cysts, in Kaye AH, Laws ER Jr (eds): Brain Tumors: An Encyclopedic Approach, ed 3. Philadelphia: Elsevier, 2012, pp 831-848

32. Kaylie DM, Warren FM III, Haynes DS, Jackson CG: Neurotologic management of intracranial epidermoid tumors. Laryngoscope 115:1082-1086, 2005

33. Khan RB, Giri DD, Rosenblum MK, Petito FA, DeAngelis LM: Leptomeningeal metastasis from an intracranial epidermoid cyst. Neurology 56:1419-1420, 2001

34. King JE: Extradural diploic and intradural epidermoid tumors (cholesteatoma). Ann Surg 109:649-688, 1939

35. Kobata H, Kondo A, Iwasaki K: Cerebellopontine angle epidermoids presenting with cranial nerve hyperactive dysfunction: pathogenesis and long-term surgical results in 30 patients. Neurosurgery 50:276-286, 2002

36. Lewis AJ, Cooper PW, Kassel EE, Schwartz ML: Squamous cell carcinoma arising in a suprasellar epidermoid cyst. Case report. J Neurosurg 59:538-541, 1983

37. Link MJ, Cohen PL, Breneman JC, Tew JM Jr: Malignant squamous degeneration of a cerebellopontine angle epidermoid tumor. Case report. J Neurosurg 97:1237-1243, 2002

38. Lunardi P, Missori P, Innocenzi G, Gagliardi FM, Fortuna A: Long-term results of surgical treatment of cerebello-pontine angle epidermoids. Acta Neurochir (Wien) 103:105-108, 1990

39. Miyazawa N, Yamazaki H, Wakao T, Nukui H: Epidermoid tumors of Meckel's cave: case report and review of the literature. Neurosurgery 25:951-955, 1989

40. Mohanty A, Venkatrama SK, Rao BR, Chandramouli BA, Jayakumar PN, Das BS: Experience with cerebellopontine angle epidermoids. Neurosurgery 40:24-30, 1997

41. Olson JJ, Beck DW, Crawford SC, Menezes AH: Comparative evaluation of intracranial epidermoid tumors with computed tomography and magnetic resonance imaging. Neurosurgery 21:357-360, 1987

42. Recinos PF, Roonprapunt C, Jallo GI: Intrinsic brainstem epidermoid cyst. Case report and review of the literature. J Neurosurg 104 (4 Suppl):285-289, 2006

43. Rubin G, Scienza R, Pasqualin A, Rosta L, Da Pian R: Craniocerebral epidermoids and dermoids. A review of 44 cases. Acta Neurochir (Wien) 97:1-16, 1989

44. Sabin HI, Bordi LT, Symon L: Epidermoid cysts and cholesterol granulomas centered on the posterior fossa: twenty years of diagnosis and management. Neurosurgery 21:798805,1987
45. Safavi-Abbasi S, Di Rocco F, Bambakidis N, Talley MC, Gharabaghi A, Luedemann W, et al: Has management of epidermoid tumors of the cerebellopontine angle improved? A surgical synopsis of the past and present. Skull Base 18:85-98, 2008

46. Samii M, Tatagiba M, Piquer J, Carvalho GA: Surgical treatment of epidermoid cysts of the cerebellopontine angle. J Neurosurg 84:14-19, 1996

47. Sawan B, Vital A, Loiseau H, Dousset V, Strub D, Vital C: Squamous cell carcinoma developing in an intracranial prepontine epidermoid cyst. Ann Pathol 20:258-260, 2000

48. Schroeder HW, Oertel J, Gaab MR: Endoscope-assisted microsurgical resection of epidermoid tumors of the cerebellopontine angle. J Neurosurg 101:227-232, 2004

49. Shimamoto Y, Kawase T, Sasaki H, Shiobara R, Yamada F: Anterior transpetrosal approach to the prepontine epidermoids. Skull Base Surg 9:75-80, 1999

50. Sirin S, Gonul E, Kahraman S, Timurkaynak E: Imaging of posterior fossa epidermoid tumors. Clin Neurol Neurosurg 107:461-467, 2005

51. Talacchi A, Sala F, Alessandrini F, Turazzi S, Bricolo A: Assessment and surgical management of posterior fossa epidermoid tumors: report of 28 cases. Neurosurgery 42:242-252, 1998

52. Tancredi A, Fiume D, Gazzeri G: Epidermoid cysts of the fourth ventricle: very long follow up in 9 cases and review of the literature. Acta Neurochir (Wien) 145:905-911, 2003

53. Toglia JU, Netsky MG, Alexander E Jr: Epithelial (epidermoid) tumors of the cranium. Their common nature and pathogenesis. J Neurosurg 23:384-393, 1965

54. Tognetti F, Lanzino G, Manetto V, Calbucci F: Intracranial squamous cell carcinoma arising in remnant of extirpated epidermoid cyst. Br J Neurosurg 5:303-305, 1991

55. Vinchon M, Pertuzon B, Lejeune JP, Assaker R, Pruvo JP, Christiaens JL: Intradural epidermoid cysts of the cerebellopontine angle: diagnosis and surgery. Neurosurgery 36:5257, 1995

56. Yamakawa K, Shitara N, Genka S, Manaka S, Takakura K: Clinical course and surgical prognosis of 33 cases of intracranial epidermoid tumors. Neurosurgery 24:568-573, 1989

57. Yaşargil MG, Abernathey CD, Sarioglu AC: Microneurosurgical treatment of intracranial dermoid and epidermoid tumors. Neurosurgery 24:561-567, 1989

\section{Author Contributions}

Conception and design: Al-Mefty, Aboud. Acquisition of data: all authors. Analysis and interpretation of data: Al-Mefty, Aboud, Abolfotoh, Pravdenkova, Gokoglu. Drafting the article: Al-Mefty, Aboud, Abolfotoh. Critically revising the article: Al-Mefty, Aboud, Abolfotoh. Reviewed submitted version of manuscript: Al-Mefty, Aboud, Abolfotoh, Pravdenkova, Gokoglu. Approved the final version of the manuscript on behalf of all authors: Al-Mefty. Statistical analysis: Al-Mefty, Abolfotoh, Pravdenkova. Administrative/technical/material support: Al-Mefty. Study supervision: Al-Mefty.

\section{Correspondence}

Ossama Al-Mefty, Department of Neurosurgery, Brigham and Women's Hospital, 75 Francis St., Boston, MA 02115. email: oalmefty@partners.org. 